\title{
Numerical investigation of the effects of design parameters on hydraulic turbine guide vane design
}

\author{
Tasarım parametrelerinin hidrolik türbin ayar kanadı tasarımına \\ etkilerinin sayısal olarak incelemesi
}

\author{
Kutay ÇELEBIOĞLU ${ }^{*}$ iD , Fatma Zeynep AYTAÇ YILMAZ2 iD \\ 1ETU-HYDRO Water Turbine Design and Testing Center, TOBB University of Economics and Technology, Ankara, Turkey. \\ kutaycelebioglu@gmail.com \\ 2Department of Mechanical Engineering, Faculty of Engineering, Gazi University, Ankara, Turkey. \\ fzaytac@gmail.com
}

\begin{abstract}
Francis type hydraulic turbines that have a wide range of operating range for head and flow rates are commonly used in hydropower generation. Every power plant needs its custom designed turbine because the available head and flow rates, which are the main parameters to start the design process, are different for each plant. Guide vanes are the only movable parts of Francis turbines. They control the flow rate through the turbine. In this study, a generalized Computational Fluid Dynamics (CFD) aided design methodology is developed and applied to the design of the turbines of two different power plants. The effects of several parameters, including the shape of the guide vane profile, eccentricity, blade angles, overlapping percentage of the blades, number of guide vanes, and rotor-stator distance are examined. Results are investigated for each parameter in terms of flow physics and important outcomes are determined for turbine designers.
\end{abstract}

Keywords: Simulation, Guide vane, Hydro-turbine design, CFD.
Öz

Francis tipi su türbinlerinin çeșitli debi ve düșü değerlerini kapsayan geniş bir çalışma aralığı olduğu için güç üretiminde sık kullanılırlar. Her hidroelektrik santralin kendi özelliklerine uygun türbin tasarımına ihtiyacı vardır; çünkü türbin tasarım prosesinin en önemli iki parametresi olan düşü ve debi her santral için farklıdır. Ayar kanatları türbinin tek hareket ettirilebilen parçasıdır. Türbinden geçen debiyi düzenlemeye yararlar. Bu çalışmada, Hesaplamalı Akışkanlar Dinamiği (HAD) bazlı bir genelleștirilmiș tasarım yöntemi geliștirilerek iki ayrı hidroelektrik santralin türbin tasarımına uygulanmıștır. Ayar kanadı profili, merkezden kaçıklık, kanat açıları, kanatların örtüșme yüzdeleri, ayar kanat sayısl, rotor-stator mesafesi gibi tasarm parametrelerinin etkileri incelenmiştir. Sonuçlar her bir parametre için incelenmiș, akış fiziği ve türbin tasarımclları açısından önemli bulgular belirlenmiștir.

Anahtar kelimeler: Simülasyon, Ayar kanadı, Su türbini tasarımı, HAD.

turbine at the best efficiency point where the hydraulic losses reach their minimum values [5].

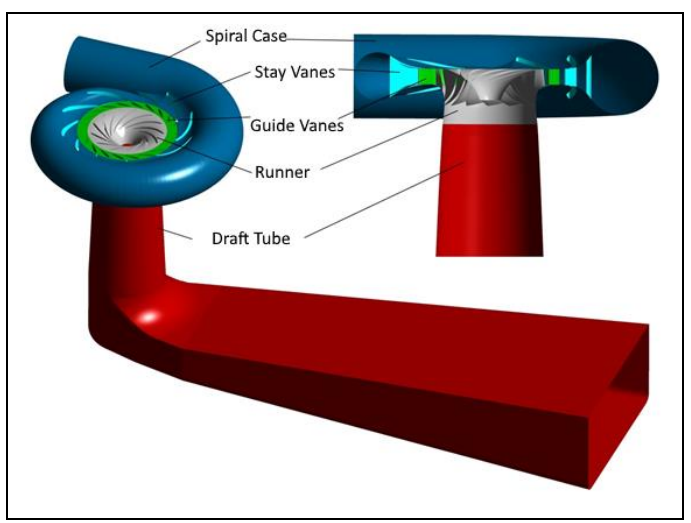

Figure 1. Main components of a Francis turbine.

In this work, Computational Fluid Dynamics simulations are performed to design guide vanes for two specific turbines that are implemented in actual hydroelectric power plants (HEPP). The effects of several parameters on design are examined numerically. These parameters are given as:

${ }^{*}$ Corresponding author/Yazışılan Yazar 
- Shape of Hydrofoil: Different NACA profiles for the guide vane hydrofoils are simulated to observe the effect of the shape on outlet flow angles, head loss, meridional velocity profile and torque exerted by the flow to the guide vanes,

- Eccentricity of the guide vane: Eccentricities, distance between the position of the guide vane shaft and the line passing through the leading edge of the guide vanes, are investigated in order to obtain the limits and ratios of maximum and minimum torque so that the designer is able to design a proper regulating mechanism for safe operation of the turbine,

- Overlapping ratio: This is the percentage of blades that overlap one another. This ratio is used for proper sealing of the turbine during full closure of the turbine and it affects safety. As this ratio is changed, the number and length of guide vanes change; therefore, all flow parameters such as flowrate, flow angle and head loss are affected by this parameter,

- Rotor-stator distance: The rotor-stator relationship causes the flow in a Francis turbine to be transient. As the runner blades are exposed to the wakes formed at the outlet of guide vanes, they experience significant velocity, flow angle and pressure change which results in a critical dynamic load on the runner. Also, pressure train generated by the rotating runner affects the flow exit angles of the guide vanes. As the distance between rotor and stator increases, the flow in this passage becomes uniform. On the other hand, the swirl of water generated by the guide vane, passes through a longer uncontrolled distance and deviates from the optimum angles of swirl for the runner operation.

Detailed numerical simulations for these two case studies are performed in order to understand the relationship between these critical parameters and to provide an insight to the designer. A prior knowledge of these effects can significantly reduce the time and effort, in addition, the generalized results can be used by hydraulic designers to predict the effects of several design parameters on the flow structure without performing further CFD simulations.

\section{Methodology}

Each turbine necessitates a unique design due to different values of head and discharge of the power plant under consideration. The main purpose of each design is to improve the efficiency for the whole operating range [6],[7]. During the guide vane design process, the procedure given in Figure 2 is followed. The first step is preliminary design. To determine the initial dimensions, head and discharge values are used. A blade profile to start CFD simulations is generated as an output of the preliminary design. This geometry is changed and analyzed by CFD tools until it provides a flow with uniform velocity and pressure distribution which has no separation and enters the runner with a proper angle. The iterative procedure continues until the required flow conditions are met. When designing the guide vanes, hydrofoil profiles are used to minimize the losses and pressure fluctuations while supplying the necessary flow to the turbine. Thus, a change in blade profile may result in severe changes in flow properties and efficiency. A thinner blade profile may result in better hydrodynamic properties but may not be safe, structurally. So, in this iterative procedure, the blade profiles are also checked structurally as the blades are the only mechanism that are available in Francis turbines to safely stop the operation. If the geometry does not provide structural safety, the geometrical model is changed and CFD analyses are repeated as given in Figure 2.

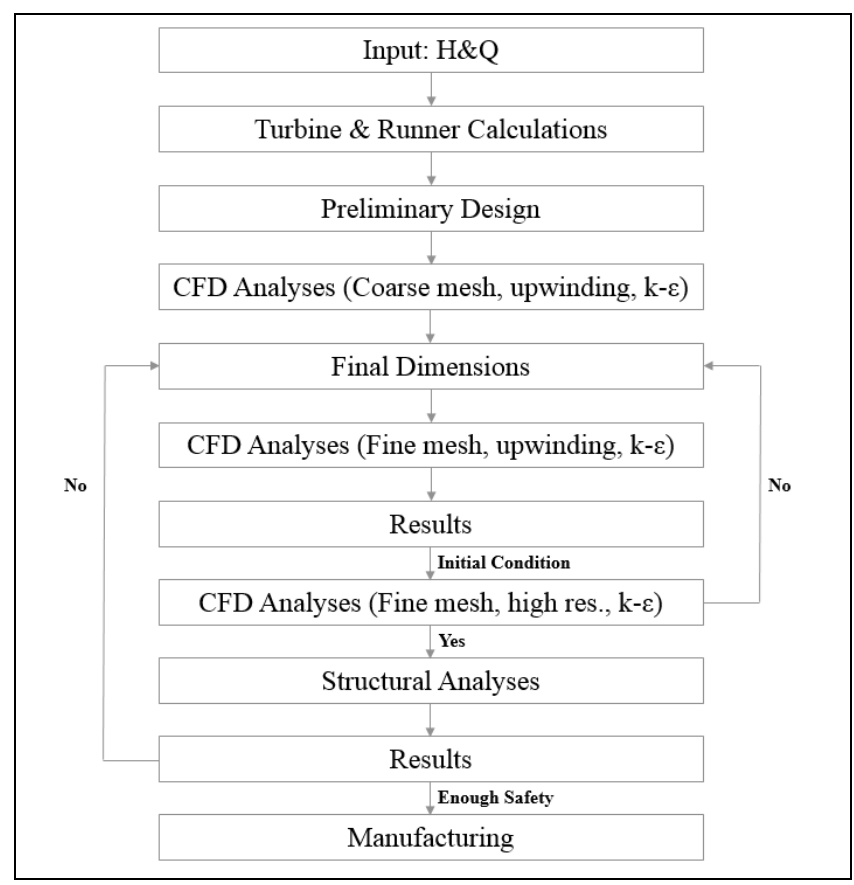

Figure 2. CFD aided design procedure for the guide vanes.

The governing equations are three-dimensional Navier-Stokes equations for incompressible Newtonian fluids as given in Equation (1) where water is the medium used for turbines.

$$
\begin{gathered}
\frac{\partial u_{j}}{\partial x_{j}}=0 \\
\rho\left(\frac{\partial u_{i}}{\partial t}+u_{j} \frac{\partial u_{i}}{\partial x_{j}}\right)=F_{i}-\frac{\partial p}{\partial x_{i}}+\mu \frac{\partial^{2} u_{i}}{\partial x_{j}^{2}}
\end{gathered}
$$

The flow inside the turbine is solved by the Reynolds averaging Navier-Stokes equations. Reynolds averaging is applied to momentum and continuity equations and the variables are decomposed into "average" and "turbulent" components. A two-equation turbulence model is used. ANSYS CFX 15.0 is used for the CFD analyses. A detailed description of the numerical model and solution procedure can be found in [8].

The first step in geometric design is modeling the guide vane in BladeGen. The obtained profile is then meshed with hexahedral elements in TurboGrid module. CFD analyses are performed by using boundary conditions as total pressure inlet and mass flow rate outlet, solving three dimensional Navier-Stokes equations. With the help of CFD tools, undesired flow conditions (such as separation) are observed, as well.

The two-equation model that is used in this work is the $\mathrm{k}-\varepsilon$ turbulence model. This well-known turbulence model is extensively used in turbine design and optimization [11],[12]. $k-\varepsilon$ turbulence model is used in order to model the complex characteristic of the flow more accurately throughout the hydraulic system and it gives practical solutions in turbine design and optimization in steady flow calculations [13]-[16]. 
Throughout the study, two advection schemes are used; upwind and high resolution. In preliminary design analyses, a coarse mesh is used with an upwind advection scheme in order to save time and computer effort. After the dimensions are determined, the number of elements in the mesh is increased and the rest of the analyses are performed with high resolution advection scheme to obtain more accurate results. Turbine simulations with the high resolution scheme provides better results than the ones with the upwind scheme [15]. Also, high resolution advection is the most sensitive scheme to mesh error. So a solution criterion is set for a residual value of $10^{-5}$ and mesh independence study is performed. Figure 3 shows the results of the mesh independence study. Mean outlet velocity values are checked to see whether the results are independent of element number. The results do not change significantly with mesh size but it was observed that approximately $400 \times 10^{3}$ elements are enough to obtain an accurate solution.

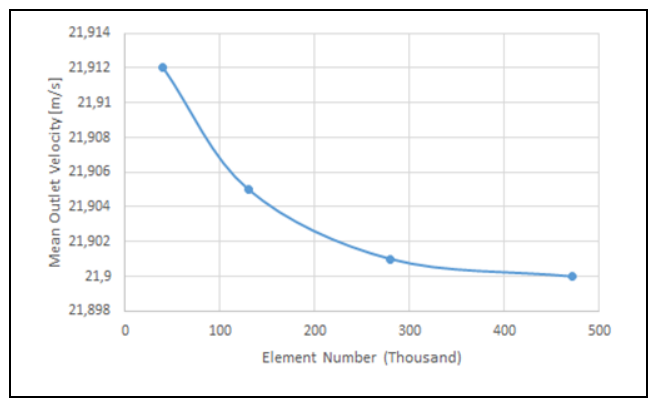

Figure 3. Mesh independence study.

CFD analyses are performed by using total pressure inlet and mass flow rate outlet boundary conditions. Results are evaluated by using post processing tools for conditions such as uniformity, pressure distribution, separation etc. To investigate the relationship between the rotor and the stator, their meshes are connected to each other. Frozen rotor approach is used for the process. Although the flow in Francis turbines is transient due to the rotor-stator interaction, the analyses are performed in 3D and steady-state by using this approach. Per this method, two components are evaluated separately. Guide vane (stator) is assigned as the stationary reference system whereas the runner (rotor) is assigned as the rotational reference system. At the interface, a local reference frame transformation is performed. By performing the analyses in steady-state, computational power and time are saved. A sample hexahedral mesh of the guide vane is shown in Figure 4.

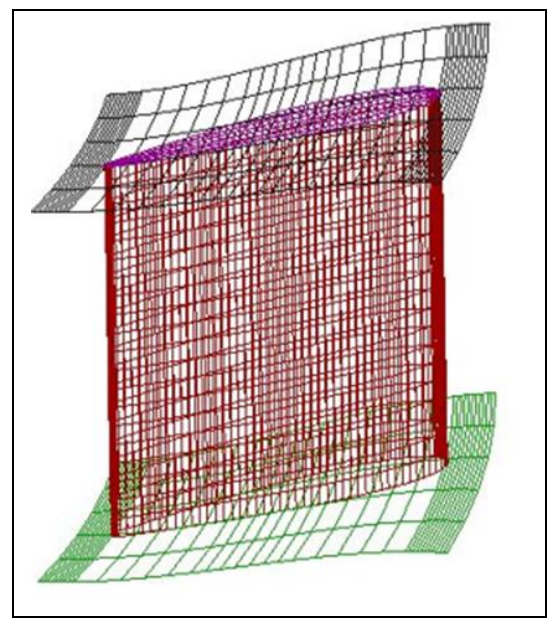

Figure 4. Computational domain of the guide vanes.

\subsection{Preliminary parametric design}

As the aim of this study is to give a better judgement to the designer for designing the guide vanes of a Francis turbine, the parameters that define the preliminary design of the guide vanes are investigated. These parameters are shown in Figure 5. Most of these parameters are specific to turbine manufacturers and change from turbine to turbine. As no established guideline exists, experience from previous studies are used here as a guideline.

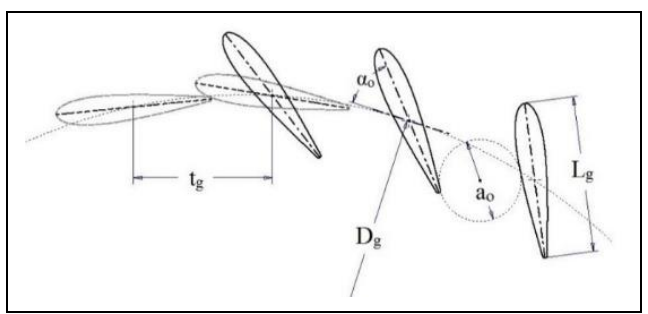

Figure 5. Guide vanes [10].

The diameter of the circle passing from the center of the guide vanes is denoted by $\mathrm{D}_{\mathrm{g}}$. This is chosen as 1.16 times the runner inlet diameter [9]. The height of the guide vanes is equal to the height of the runner inlet [1]. The parameter $\alpha_{0}$ in Figure 5 represents the guide vane opening. The number of guide vanes is usually chosen as 12,16 or 24 .

The length of the blades is calculated such that they do not permit water passage in the closed position. To ensure this requirement, the trailing edge of the blade is overlapped on the pressure side of the guide vane leading edge at closed position, as shown in Figure 5. This is ensured by selecting the distance between guide vane centerlines $\left(t_{g}\right)$ slightly smaller than the guide vane camber length $\left(L_{g}\right)$ as given in Eq 2 .

$$
\frac{L_{g}}{t_{g}} \cong 1.1
$$

Then, the required guide vane length to provide roughly $10 \%$ overlap at the closed position is

$$
L_{g}=\frac{\pi D_{g}}{\text { number of guide vanes }} * \frac{1}{0.9}
$$

The thickness of the guide vane blades is determined by NACA profiles.

\section{Result}

\subsection{CFD aided final design}

An extensive set of simulations are performed to design guide vanes for two hydroelectric power plants, i.e. Atakoy and Yuvacik, which will be named HEPP 1 and HEPP 2 from this point on. Various guide vane geometric design parameters are used in simulations and the final designs are given in Table 1.

In order to demonstrate the final design outputs as an example, the details of the guide vanes simulations are given for the first hydroelectric power plant, HEPP 1 . The plant has a net head of $66.8 \mathrm{~m}$ and flow rate of $4.25 \mathrm{~m}^{3} / \mathrm{s}$. The diameter $D_{g}$, and the dimensions of the guide vanes, $L_{g}$ and $b_{0}$, are determined, then blade profiles are assigned. The guide vanes are divided into 477204 nodes and 453152 elements for the CFD analyses. Figure 6 shows the solid model and mesh of the guide vane. A symmetric hydrofoil profile, NACA 0018 , is chosen as the final hydrofoil shape for the blades. The inlet flow angle is computed 
as 37.1 degrees, whereas the outlet angle is 29.6 degrees. The velocity for the outlet is computed to be $21.9 \mathrm{~m} / \mathrm{s}$. A total pressure of $731.4 \mathrm{kPa}$ is reached at the outlet.

Table 1. Final simulation results for the designed guide vanes.

\begin{tabular}{ccc}
\hline Guide vane property & HEPP 1 & HEPP 2 \\
\hline Height, bo & $152 \mathrm{~mm}$ & $192.03 \mathrm{~mm}$ \\
$\begin{array}{c}\text { Diameter of the circle passing } \\
\text { from the guide vane center, } \mathrm{D}_{\mathrm{g}}\end{array}$ & $956.5 \mathrm{~mm}$ & $806.9 \mathrm{~mm}$ \\
Number of guide vanes & 24 & 16 \\
Length, $\mathrm{Lg}$ & $140 \mathrm{~mm}$ & $176.04 \mathrm{~mm}$ \\
Thickness & NACA001 & NACA0024 \\
Blade Angle & $37.55^{\circ}$ & $35.3^{\circ}$ \\
& &
\end{tabular}

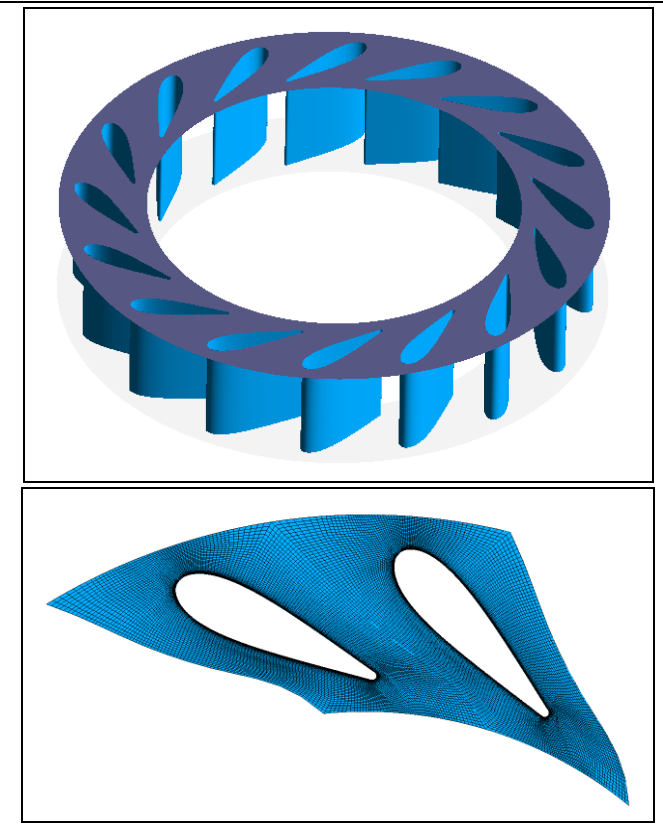

Figure 6. Solid model and mesh of the guide vane.

What was tried to be achieved in the final design is to minimize the loss through the guide vane while properly aligning the inlet and outlet flow angles of the guide vane with respect to stay vane exit and runner inlet. A clear identifier is the total pressure which indicates the energy level in the fluid. This value is lower in the regions with high losses. The velocity increases from the leading edge to the trailing edge because of the decrease in the net flow area. Wakes are formed at the trailing edge where the total pressure takes its minimum value as shown in Figure7. This region is designed to make the wakes as small as possible. Another identifier is the location of the stagnation point on the guide vane leading edge. When the flow angle between the stay vane and the guide vane is properly aligned, the stagnation point appears just at the tip of the vane for the design point as shown in Figure 7. Any other location causes the blade to be fore-loaded or back-loaded. This affects the pressure distribution and may cause flow separation on the blade.

The color-coded streamlines are shown in Figure 8. As it is seen, the flow accelerates from the leading edge of the guide vane to the trailing edge. In addition, the streamlines are uniformly distributed without any significant deviation on the third dimension. It can be assumed that the wall effect on the top and bottom boundaries of the guide vane is insignificant and the flow is mostly two-dimensional. No flow separation or interblade vortices are observed. These results are suitable for the final design of the guide vanes.

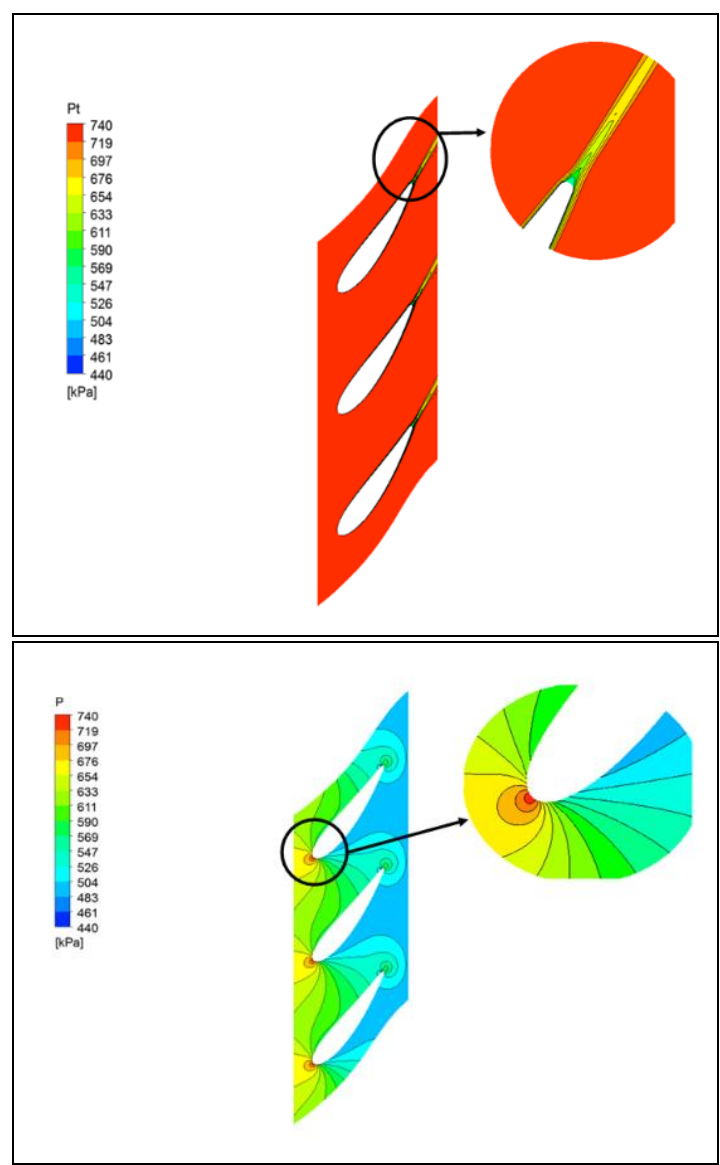

Figure 7. Total (Pt) and static (P) pressure distribution around the guide vanes.

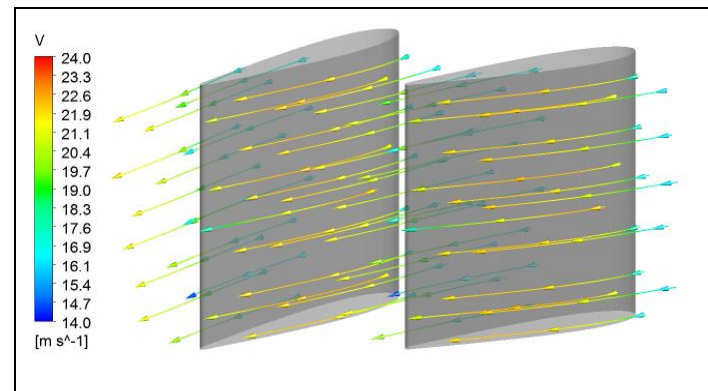

Figure 8. Streamlines around 3D guide vane blade profiles.

In order to reach this final design, the following parameters are investigated in detail.

\subsection{The effect of hydrofoil shapes on the simulation results}

Different NACA profiles for the guide vane hydrofoils are simulated to observe the effect of the shape on outlet flow angles, head loss, meridional velocity profile and torque exerted by the flow to the guide vanes. All other parameters are kept constant through the simulations. The results of the simulations for both HEPPs show similar trends so only the results of the HEPP 1 are given in Table 2 . 
Table 2. Results for NACA profiles (HEPP 1).

\begin{tabular}{cccccc}
\hline Profile & Torque (Nm) & $\begin{array}{c}\text { Meridional } \\
\text { velocity (m/s) }\end{array}$ & $\begin{array}{c}\text { Circumferential } \\
\text { Velocity } \\
\text { (m/s) }\end{array}$ & $\begin{array}{c}\text { Outlet Angle } \\
\text { (degrees) }\end{array}$ & Head Loss (m) \\
\hline NACA 0010 & -751.9 & 10.824 & 17.55 & 31.6 & 0.43 \\
NACA 0012 & -700.3 & 10.824 & 17.88 & 31.2 & 0.45 \\
NACA 0015 & -660.7 & 10.825 & 18.41 & 30.4 & 0.50 \\
NACA 0018 & -586.6 & 10.826 & 19.01 & 29.7 & 0.56 \\
NACA 0024 & -376.6 & 10.827 & 20.42 & 27.9 & 0.69 \\
\hline
\end{tabular}

In Table 2, the negative sign in front of the torque values indicates the direction. As, the guide vanes get thicker, the velocity increases because the net flow area between the guide vanes decreases. The flow is forced through a converging section between guide vanes, leading to the narrowest area at the trailing edge of the guide vane. As the vanes get thicker, the uniformity in the flow increases leading to a more uniform blade loading. A secondary effect is the decrease in pressure, thus force and torque decrease. Whereas increase in velocity leads to a higher head loss. This effect can be clearly seen in Table 2. The meridional component of the velocity depends on the discharge passing through a section, whereas circumferential velocity component at the outlet is a property of the blade trailing edge angle. One would expect thicker blades (ie. narrower flow passages) would lead to a higher meridional velocity profile and larger outlet angles; however, it has been observed that the increase in the circumferential velocity component is much higher than the increase in the meridional velocity profile and this results in smaller outlet angles. In addition, it is observed that undesired effects like flow separation and deviations occur as the blade got thicker.

Designers would want smaller torque on the guide vanes in order to minimize the cost of the control system; however, flow dynamics suggest a strong preference on thinner blade shapes both in terms of head loss and outlet angle. Therefore, a preference of a thinner blade would be more beneficial to turbine designer as long as the guide vane system is structurally safe.

\subsection{Effect of eccentricity of the guide vanes on torque}

Simulations are performed using different eccentricities and blade angles. Center of each blade rotation axis is set from the leading edge at $25,35,50,65$ and $75 \%$ eccentricity. For each eccentricity value, analyses are performed for $5^{\circ}$ increments of blade angle, for the closed position and for several blade angles between these openings. Torque values for several eccentricities are shown in Figure 9 for HEPP 1. Each line represents a single eccentricity value, for which guide vane angles are covered from the closed position to the maximum allowable opening. Additional simulations are performed around the design angle which is $37.55^{\circ}$ for HEPP 1 .

Figure 10 shows the variation of torque with blade opening for several eccentricity values for HEPP 2 . As seen from Figures 9 and 10, the trends in both HEPP 1 and HEPP 2 are similar. The design angle is $35.05^{\circ}$ for HEPP 2 .

In Figures 9 and 10, the negative torque values indicate a hydraulic opening tendency in the blade, whereas positive torque values represent closing tendency. It should be noted that the guide vanes show a very strong opening tendency at low opening values. This trend starts to change to closing tendency after 15 degrees. This is true for all eccentricity values. In all cases, the maximum torque value is observed at almost closed positions. A 0.5 eccentricity value can be considered a neutral position where the shaft supporting the guide vane (i.e, its rotation axis), is just in the middle of the chamber length. Any rotation axis further towards the trailing edge should be avoided by the designer as the torque values start to increase significantly higher than the neutral position. A position closer to the leading edge may be beneficial in terms of hydraulic loads.

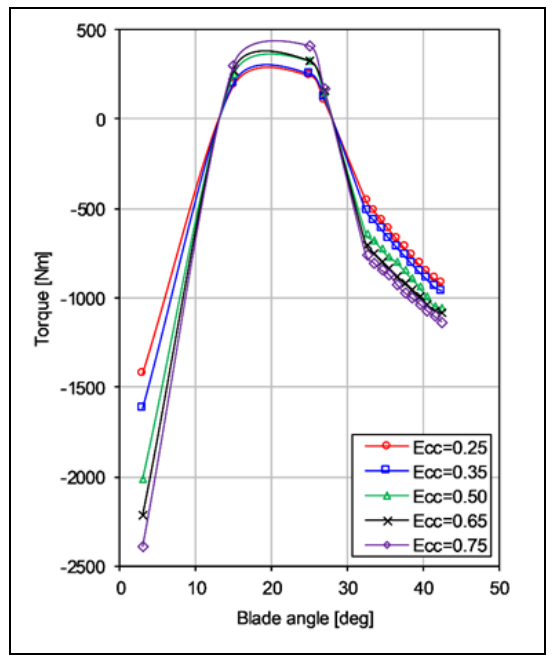

Figure 9. Variation of torque with blade opening for several eccentricity values for HEPP 1.

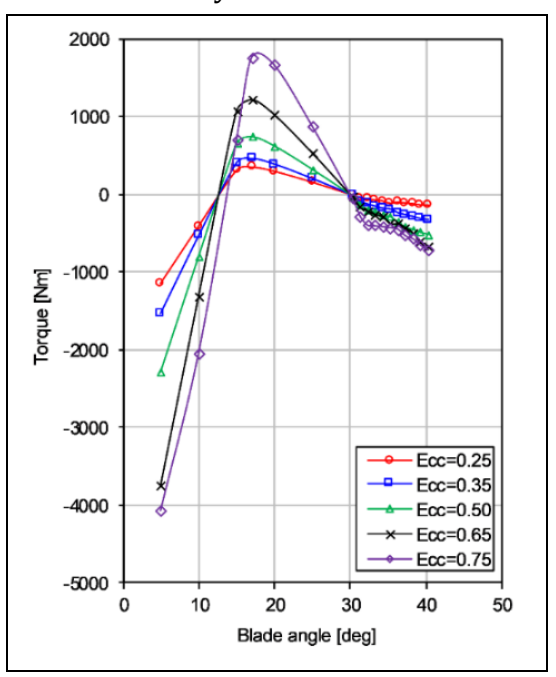

Figure 10. Variation of torque with blade opening for several eccentricity values for HEPP 2. 


\subsection{The effects of overlapping percentages on number of blades and simulation results}

Guide vanes are the primary safety mechanisms for Francis turbines. They are not only used as a regulating mechanism for power and flow but also used as an emergency shutoff option. Therefore, during closure, these vanes prevent water passing through the turbine by blocking the flow area. A full blockage is achieved in practice by overlapping a certain percentage of the leading edge to the trailing edge of the following blade as seen in Figure 5. This makes $t_{g}$, the distance between the rotation axis of two consecutive blades, different then $L_{g}$, the chamber length of the blade. In practice, a common rule of thumb is to use a $10 \%$ difference between these values.

In order to investigate the effect of changing this value, a series of simulations are performed using different overlapping percentages. The overlapping percentages investigated are 5, $10,20,30,40$ and $50 \%$. Increasing this value causes an increase in the required number of blades as seen in Table 3.

Table 3. The effect of overlapping ratio on number of blades and torque (HEPP 1).

\begin{tabular}{ccc}
\hline $\begin{array}{c}\text { Overlapping } \\
\text { Ratio [\%] }\end{array}$ & $\begin{array}{c}\text { Number of blades } \\
\text { for HEPP 1 }\end{array}$ & $\begin{array}{c}\text { Number of blades } \\
\text { for HEPP 2 }\end{array}$ \\
\hline 5 & 22 & 15 \\
10 & 24 & 16 \\
20 & 26 & 17 \\
30 & 28 & 19 \\
40 & 30 & 20 \\
50 & 32 & 22 \\
\hline
\end{tabular}

The effects of overlapping ratio on the number of blades and consequently on torque, head loss, and velocity, are investigated. The effects of the overlapping ratio on torque are shown in Figure 11.

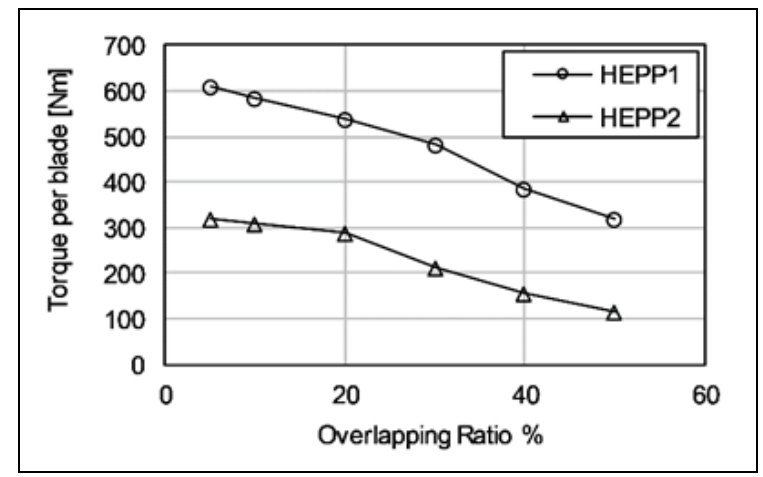

Figure 11. The variation of torque with overlapping ratio.

Also shown in Figure 11 and Table 3, overlapping ratio increase results in an increase in the number of blades to cover the entire speed ring and this increase is accompanied by a decrease in torque magnitude. This is expected as the number of blades increase; the length of the blade $\left(L_{g}\right)$ decrease, resulting in a smaller torque. What is of more interest is the total torque transferred to the regulating ring. This total torque value can be obtained by multiplying the number of blades with the blade torque as seen in Figure 12. This maximum value is observed around \%10 overlapping ratio, which supports the industry standard.

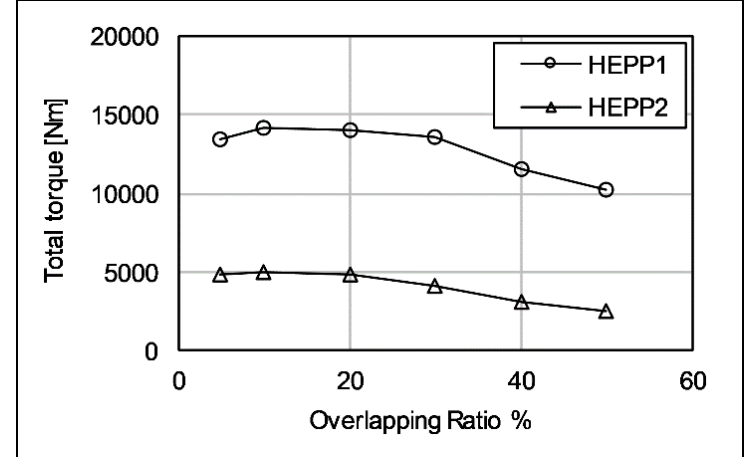

Figure 12. The variation of total torque with overlapping ratio.

When head loss is studied, an increase is observed with increasing overlapping ratio as shown in Figure 13. Although the blades become shorter as the overlapping ratio increases, the increase in the number of blades results in reduction of the total cross-sectional area and increase in the meridional velocity value. This leads to a higher loss through the guide vanes.

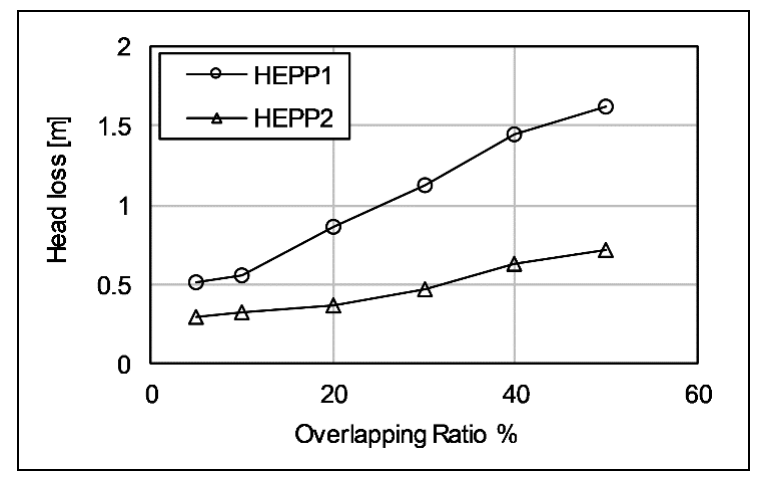

Figure 13. Change of head loss with overlapping ratio.

The established industry standard of approximately \%10 overlapping ratio is supported by the simulations as the torque is maximized and the head loss is minimized around this value. Still $5-15 \%$ solutions proved viable and the designer may choose such a ratio depending on the structural and operational constraints.

\subsection{The effects of rotor-stator distance on head loss}

Transient effects between the stationary and rotational components cannot be prevented because of the stagnation point at the leading edge and the wake at the trailing edge. Runner blades are exposed to significant changes in velocity, pressure and flow angle as the flow passes through the wakes formed by the guide vanes. Reducing the dynamic loads on the runner provides smooth operation.

The pressure fluctuations are caused by the rotation of the runner in the stationary flow field that the guide vanes generate. The frequency and amplitude of these pressure fluctuations can be controlled by changing the number of runner blades and guide vanes, adjusting the distance $(\Delta)$ between these two components, altering the thickness and shape of the leading edge of the runner and changing the shape of the trailing edge of the guide vane [7].

Although the relationship between these components is transient, in the design process, analyses are performed in steady-state to save time and computational power. Transient simulations are prohibitively expensive. When a transient 
phenomenon is analyzed in steady-state, a form of approximation is necessary. This is achieved by the frozen rotor approach where the location of the runner with respect to the guide vane is frozen in time when the results are transferred from the stationary frame to the rotating frame. A descriptive value of this phenomena is the maximum value of the pressure on the runner inlet section. When the runner is rotating, the leading edge of the runner blade is exposed to stagnation pressure. This stagnation point rotates with the runner creating a pressure train which is observed at the outlet section of the guide vane, when the distance between the runner inlet and the guide vane outlet is small. As the distance between the guide vane and the runner increase this effect is less pronounced and the maximum observed pressure is reduced. It is desirable to have a smaller amplitude in this fluctuating pressure component. In this part of the parametric study, the effect of the distance $(\Delta)$ between the runner and the guide vane blades on the runner maximum inlet pressure and the guide vane loss is investigated. The maximum pressure value is reduced significantly for both HEPPs when the ratio of the gap $(\Delta)$ to the guide vane circle diameter $\left(D_{g}\right)$ is higher than 0.05 . Increasing this distance has a positive effect on the runner maximum inlet pressure accompanied by a slight decrease in the guide vane loss as seen in Figures 14 and 15.

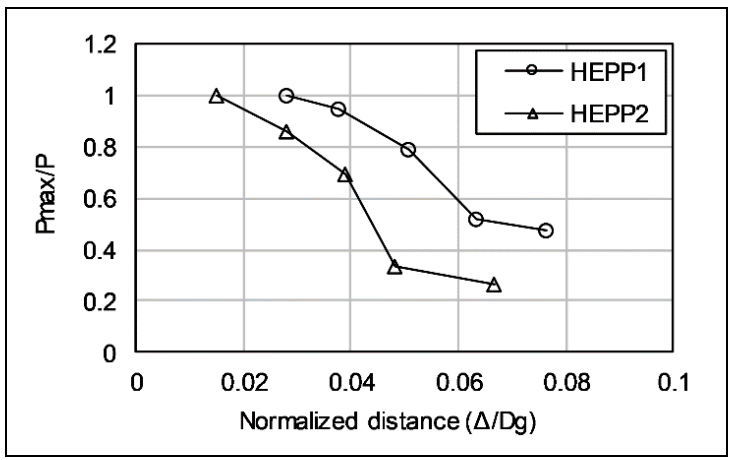

Figure 14. Normalized pressure vs normalized rotor-stator distance.

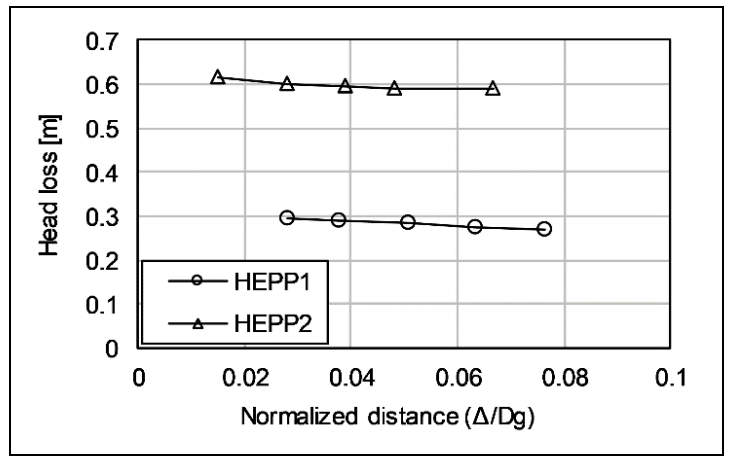

Figure 15. Head loss vs normalized rotor-stator distance.

A practical suggestion for the designer is that the normalized rotor-stator distance $\left(\Delta / D_{g}\right)$ should be kept at a minimum of 0.05 . Higher values may also be used by taking into the account that the circulation is constant between the guide vane and the runner leading edge as the velocity momentum is conserved.

\section{Discussions and Conclusion}

A design methodology for guide vanes is developed and applied to the design of the turbine guide vanes of two different hydroelectric power plants. Several standard criteria, such as pressure and velocity distributions, magnitude of the head loss, location of the stagnation point and the flow angle at the runner inlet are considered to design the blades. Iterations are performed according to the utilized methodology until the predetermined criteria are satisfied. A further detailed parametric study is performed to investigate the effects of several design parameters on flow variables such as shape of hydrofoils, eccentricity of the guide vanes, overlapping ratio, and rotor-stator distance.

Among the parameters, different NACA profiles for the guide vane hydrofoils are simulated to see the effect of the shape on outlet flow angles, head loss, meridional velocity profile and torque exerted by the flow to the guide vanes. Flow dynamics suggest a strong preference on thinner blade shapes both in terms of head loss and outlet angle. So, a preference of thinner blade would be more beneficial to turbine designer as long as the guide vane system is structurally safe.

Moreover, different eccentricities are investigated in order to obtain the limits and ratios of the maximum and the minimum torque so that the designer can design the proper regulating mechanism for safe operation of the turbine. When the rotation axis is towards the trailing edge, the torque values are significantly higher than the neutral position. So, eccentricities should be avoided by the designer. A position closer to the leading edge may be beneficial in terms of hydraulic loads.

As the overlapping ratio is changed, the number and length of the guide vanes change, hence all flow parameters such as flowrate, flow angle and head loss are affected by this parameter. The established industry standard of roughly $\% 10$ overlapping ratio is supported by the simulations, as the torque is maximized and the head loss is minimized around this value. Still 5-15\% solutions are viable and designers may choose such ratios depending on the structural and operational constraints.

Lastly, the pressure train that is generated by the rotating runner affects the flow exit angles of the guide vanes. As the distance between the rotor and the stator increases, the flow in this passage becomes uniform. A prior knowledge of this gap is useful for the designer. A practical suggestion is made for the designer such that the normalized rotor-stator distance $\left(\Delta / D_{g}\right)$ should be kept at a minimum of 0.05 . Higher values may also be used by taking into the account that the circulation is constant between the guide vane and the runner leading edge as long as the velocity momentum is conserved.

\section{Acknowledgments}

The computational facilities of TOBB ETU Hydro Energy Research Laboratory, financially supported by Ministry of Development, were utilized.

\section{References}

[1] Odesola IF, Oririabre JI. "Development of a 5kW Francis turbine runner using computational fluid dynamics". African Research Review, 7(30), 178-195, 2013.

[2] Khare R, Prasad V, Kumar S. "CFD approach for flow characteristics of hydraulic Francis turbine". International Journal of Engineering Science and Technology, 2(8), 3824-3831, 2010.

[3] Drtina P, Sallaberger M. "Hydraulic Turbines-Basic principles and state of the art computational fluid dynamics applications". Proceedings of the Institution of Mechanical Engineers, Part C: Journal of Mechanical Engineering Science, 213, 85-102, 1999. 
[4] Muntean S, Susan Resiga R, Bernad S, Anton I. "Analysis of the GAMM Francis turbine distributor 3D flow for the whole operating range and optimization of the guide vane axis location". $6^{\text {th }}$ International Conference on Hydraulic Machinery and Hydrodynamics, Timisoara, Romania, 21-22 October 2004.

[5] Roghelia A, Desai J, Soni V, Chauhan V. "Non-dimensional statistical approach to design guide vanes of Francis turbines". Proceedings of the $37^{\text {th }}$ National \& $4^{\text {th }}$ International Conference on Fluid Mechanics and Fluid Power, Chennai, India, 16-18 December 2010.

[6] Brekke H. "Design, performance and maintenance of Francis turbines". Global Journal of Researches in Engineering Mechanical and Mechanics Engineering, 13(5), 29-40, 2013.

[7] Flores E, Bornard L, Tomas L, Liu J, Couston M. "Design of a large Francis turbine using optimal methods". 26 th IAHR Symposium on Hydraulic Machinery and Systems, Beijing, China, 19-23 August 2012.

[8] Ansys CFX 15.0 User's Guide, Ansys, 2013.

[9] Krivchenko, G. I. Hydraulic Machines: Turbines and Pumps. Boca Raton, FL, Lewis Publishers, 1994.

[10] European Small Hydropower Association. "Guide on How to Develop a Small HydroPower Plant". https://energiatalgud.ee/img_auth.php/a/ab/Guide_on_ How_to_Develop_a_Small_Hydropower_Plant.pdf, 2004.
[11] Drtina P, Sallaberger M. "Hydraulic turbines-basic principles and state of the art computational fluid dynamics applications". Proceedings of the Institution of Mechanical Engineers, Part C: Journal of Mechanical Engineering Science, 213, 85-102, 1999.

[12] Nennemann B, Vu TC, Farhat M. "CFD prediction of unsteady wicket gate-runner interaction in Francis turbines: A new standard hydraulic design procedure". HYDRO 2005 International Conference and Exhibition, Villach, Avustria, 17-20 October 2005.

[13] Carija Z, Mrsa Z, Fucak S. "Validation of Francis water turbine CFD simulations". Strojarstvo, 50(1), 5-14, 2008.

[14] Wu J, Shimmei K, Tani K, Nikura K, Sato J. "CFD-based design optimization for hydro turbines". Journal of Fluid Engineering, 129, 159-168, 2007.

[15] Carija Z., Mrsa Z. "Complete Francis turbine flow simulation for the whole range of discharges". $4^{\text {th }}$ International Congress of Crotian Society of Mechanics, Bizovac, Croatia, 18-20 September 2003.

[16] Souza LCEO, Moura MD, Junior ACPB, Nilsson H. "Assesment of turbulence modelling for CFD simulations into hydroturbines: spiral casings". 17th International Mechanical Engineering Congress, Sao Paulo, Brazil, 10-14 November 2003. 